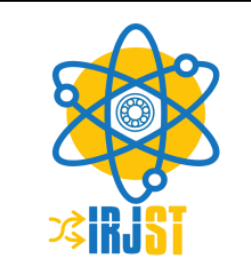

Available online at https://www.irjst.com/

International Research Journal of Science and Technology

ISSN:2707-3955

DOI: https://doi.org/10.46378/irjst.2019.010108

\title{
Synthesis and Characterization of Tin (II) and Lead (II) Complexes with Benzylidene Aniline Ligand
}

\author{
Tolessa Egeta Dufera*, Sofani Tafesse and Ramesh Duraisamy \\ Department of Chemistry, Arba Minch University, Arba Minch, Ethiopia.
}

Published : 2019

\begin{abstract}
The Schiff base (Benzylideneaniline molecule) and its complexes with Sn (II) and $\mathrm{Pb}$ (II) have been synthesized and characterized by various spectroscopic and electro-analytical techniques. The ligand, Benzylideneaniline has been synthesized by condensation reaction of benzaldehyde and aniline.The metal complexes were prepared by mixing of saturated solutions of metal salts and ligand in 1:2 ratios in methanol and Dimethylsulfoxide solvents, followed by their characterization using magnetic susceptibility, molar conductivity, chloride estimation and spectral studies. It was found that titled organic ligand acts as monodentate and in both complexes it is proposed to be interacted in metal to ligand 1:2 ratio with the metals to form organotin(II) and organolead (II) complexes through the direct method. Overall experimental results show that a diamagnetic and square planar geometry of both complexes formed.
\end{abstract}

Key Words

Schiff base,

Benzylideneaniline,

Organotin,

Organolead,

Syntheses,

Characterization.

Copyright (C) 2019:Tolessa Egeta Dufera, Sofani Tafesse and Ramesh Duraisamy. This is an open access distribution, and reproduction in any medium, provided Access article distributed under the Creative Commons Attribution License the original work is properly cited License, which permits unrestricted use.

Citation: Tolessa Egeta Dufera, Sofani Tafesse and Ramesh Duraisamy. "Synthesis and Characterization of Tin (II) and Lead (II) complexes with Benzylidene Aniline Ligand", International Research Journal of Science and Technology, 1(1), 56-65, 2019

\section{Introduction}

Schiff base was invented by Hugo Schiff, which is named after him [1]. Basically these are compounds with a functional group which possess a carbonnitrogen double bond with the nitrogen atom connected to an aryl or alkyl group not with hydrogen. In general sense Schiff bases, could be represented by the general formula $\mathrm{R}_{1} \mathrm{R}_{2} \mathrm{C}=\mathrm{NR}_{3}$, where $\mathrm{R}$ is an organic side chain. Some of them are restricted to the secondary aldimines (like azomethines as the carbon is attached with a hydrogen atom) with the general formula $\mathrm{R}_{1} \mathrm{R}_{2} \mathrm{R}_{3} \mathrm{CH}=\mathrm{NR}$ ' [2].

\footnotetext{
* Corresponding author: Tolessa Egeta Dufera

Department of Chemistry, Arba Minch University, Arba Minch, Ethiopia.

Email: tolessaegeta@gmail.com; drrameshmcas@gmail.com
}

There are a number of ways developed since the invention of the first Schiff base. The following are the major ways to get several of their kinds;

The most common method for preparing imines is the original reaction discovered by Schiff base [4]. As described above, it consist the reaction of an Aldehydes or Ketones with a primary amine and elimination of one water molecule (Scheme 2) and this reaction can be accelerated by acid catalysis and is generally carried out by refluxing a mixture of a carbonyl compound and an amine in order to remove water molecule [4].

Alkyl and aryl cyanides react smoothly with phenols and their ethers producing ketimines in very good yields in the presence of an acid catalyst (Scheme 1-3). The reaction is performed by mixing the nitrile and phenol in ether and saturating the solution with gaseous $\mathrm{HCl}$, whereas, for less reactive phenols, $\mathrm{ZnCl}_{2}$ must be used [6]. 
$\mathrm{R} \longrightarrow \mathrm{C} \longrightarrow \mathrm{R}+\mathrm{R}-\mathrm{NH}_{2} \rightleftharpoons$

Aldehyde or Ketone
Primary amine

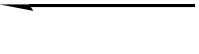

Carbinolamine<smiles>C=C=C</smiles>

Scheme 1.General reaction for the formation of Schiff bases.

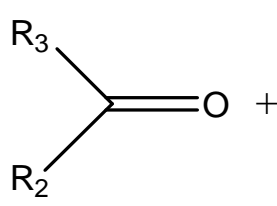<smiles>N</smiles><smiles>[R7]N(CC)C([R])([R6])O</smiles><smiles>[R]N=C([R])[R]</smiles>

Scheme 2.Schiff base reaction for the preparation of imines[5].

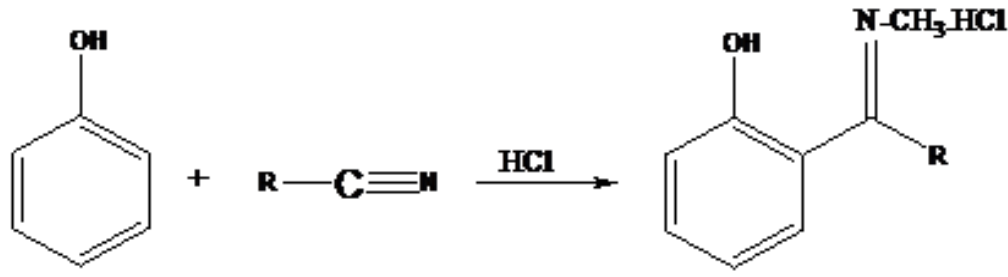

Scheme 3. Synthesis of ketimines from phenols and nitriles [7]

Coordination chemistry is the rapid growing branch of chemistry and deals with the interaction between the metal and ligand. A Schiff base is a compound with a functional group that consists of an azomethine linkage or an amino group. It is formed by the condensation reaction between Aldehydes and Ketones with a primary amino group.Azeotropic distillations followed by the treatment with molecular sieves ensure the complete removal of water molecules from the reaction mixture.

Nowadays, the research field dealing with Schiff base coordination chemistry has expanded enormously. The importance of Schiff base complexes for bioinorganic chemistry, biomedical applications, supramolecularchemistry, catalysis and material sciences, marine applications, separation and encapsulation processes and formation of compounds with unusual properties and structures has been well recognized [8, 9]. They have gained significant interest in the area of drug research and development owing to their broad bioactivities like antibacterial,antituberculosis, anti-microbialand anticonvulsant [10-14] activities. Especially, organometallic compounds containing lead and tin are commercially significant[15].Organotin with organic groups can be powerful fungicides and their demand increased worldwide production of organotin compounds with a novel Schiff base ligand during the last 50 years [16].

\section{Experimental Details}

2.1 Chemicals:Hydrated tin chloride, Lead chloride, Aniline, Calcium chloride and benzaldehyde.

\subsection{Instruments and Equipment}

NMR Spectrometry: NMR spectra of the studied samples were recorded by using BRUKER $400 \mathrm{MHz}$ $\left({ }^{1} \mathrm{H}-\mathrm{NMR}\right)$ and $100.06 \mathrm{MHz}\left({ }^{13} \mathrm{C}-\mathrm{NMR}\right)$ ultra-shielded NMR spectrometer.

FTIR Spectroscopic Study:Infrared (IR) spectrum of samples was also recorded using a Perkin-Elmer 
(model 65 FT-IR spectrophotometer in the range of $4000-400 \mathrm{~cm}^{-1}$ using $\mathrm{KBr}$ pellet.

UV-visible Spectroscopic Study: The electronic absorption spectra was carried out by using PerkinElmer UV Win Lab 6.0.3.0730 / 1.61.00 Lambda 900 UV-vis spectrophotometer in $200-800 \mathrm{~nm}$ regions.

Melting Point:Melting point of the samples was determined using Stuart SMP10 digital melting point apparatus.

Magnetic Susceptibility: The magnetic susceptibility of complexes was measured using Evans Balance.

Elemental Analysis: The elemental analysis was done by Flash EA-1412 Elemental Analyzer.

Molar Conductivity: Molar conductivities of complexes in suitable solvents were recorded at room temperature usingconductivity meter.

Magnetic Stirrer: Rotating and mixing during the reaction of components while heating were done. Other apparatus likeevaporating dish, glass rod, beakers, measuring cylinder, round bottom flask,volumetric flask, burette, Bunsen burner, measuring cylinder, Buchner funnel, Whatmann filter paper no. 40-42 and side arm filtration flask were used for the whole experiment.

\subsection{Synthesis of Schiff-base Ligand}

The ligand was synthesized by the condensation of $2.23 \times 10^{-4}$ mole of purified benzaldehyde and $2.23 \times 10^{-4}$ mole of aniline (1:1) molar ratio using methanol $(20 \mathrm{~mL})$ as the reaction medium in $75 \mathrm{~mL}$ roundbottom flask. Thesolutionwasstirred with magnetic stirrer until a clear solution was obtained. Then, it was refluxed for one hour at $55^{\circ} \mathrm{C}$. The resultant reaction mixture was cooled at room temperature and excess solvent removed by a rotary evaporator.Then, pale yellow colored crystals of Schiff base (scheme 4) benzylidene aniline ligand resulted and then washed with Acetone, further dried and solid product was obtained [17-32].

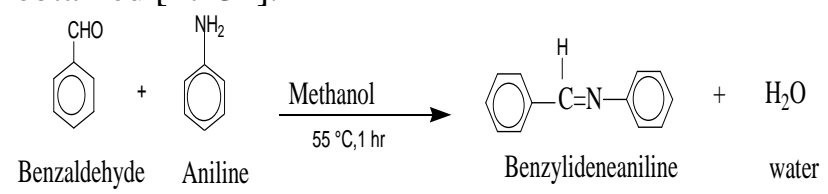

Scheme 4.Schiff basesynthesis reaction

\subsection{Synthesis of Organotin Complex}

About $2.0 \mathrm{~g}$ of $\mathrm{SnCl}_{2} .2 \mathrm{H}_{2} \mathrm{O}(0.0088 \mathrm{M}, 2.0 \mathrm{gm})$ wasdissolved in $15 \mathrm{~mL}$ of methanol and of synthesized ligand; benzylideneaniline $(0.022 \mathrm{M})$ in $25 \mathrm{ml}$ methanolwas prepared separately. Then the solution of $\mathrm{SnCl}_{2} \cdot 2 \mathrm{H}_{2} \mathrm{O}$ was added to the ligand solution while stirring with magnetic stirrer in double-necked round bottom flask with condenser.

The contents were refluxed with constant stirring with magnetic stirrer for 6 hours at $55^{\circ} \mathrm{C}$ and ultimately a green yellow solid was formed. The reaction mixture was cooled, filtered and the residue was washed five times with petroleum ether and dried under vacuum[33].

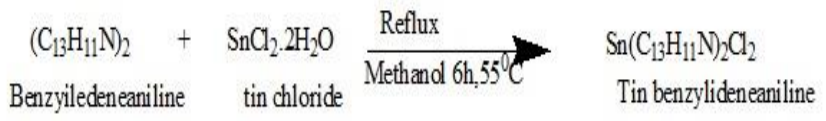

\subsection{Synthesis of Organolead Complex}

$\mathrm{PbCl}_{2} .2 \mathrm{H}_{2} \mathrm{O}(0.0064 \mathrm{M}, 2.0 \mathrm{gm})$ was dissolved in 15 $\mathrm{mL}$ of dimethyl sulfoxide and synthesized ligand, Benzylideneaniline $(0.022 \mathrm{M}, 4.0 \mathrm{gm})$ was dissolved in $25 \mathrm{ml}$ Dimethyl sulfoxide were prepared separately. Then the solution of $\mathrm{PbCl}_{2} \cdot 2 \mathrm{H}_{2} \mathrm{O}$ was added to the ligand solution while continuous stirring with magnetic stirrer in a round bottom flask provided with condenser. The contents were refluxed by constant stirring with magnetic stirrer for 6 hours at $55^{\circ} \mathrm{C}$ which yielded greenish white color solid.

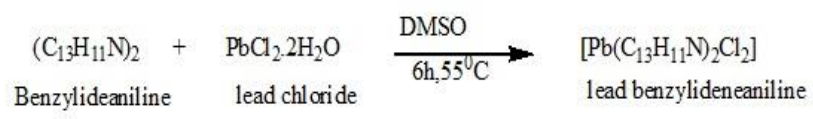

The greenish white solid was cooled isolated and the residue was washed five times with petroleum ether and then dried under vacuum pressure [34]. The purity of the complex was also checked by TLC using silica gel.

\subsection{Thin Layer Chromatography (TLC)}

The progress and purity of the reaction during the synthesis of the ligand and the complexes $\mathrm{Sn}(\mathrm{II})$ and $\mathrm{Pb}$ (II) were monitored by employing TLC in methanol as a mobile phase. The $\mathrm{R}_{\mathrm{f}}$ values were calculated using the following formula [35].

$$
\text { Retention Factor }\left(\mathrm{R}_{\mathrm{f}}\right)=\frac{\text { Distance moved by sample }}{---------------}
$$

\subsection{Test for Tin (II) and Lead (II) Ions}

About $0.2 \mathrm{mg}$ of each complex was digested in nitric acid and subjected to chloride identification using $0.1 \mathrm{M} \mathrm{AgNO} 3$ solution. A white precipitate formed confirms the presence of chloride in the sample as well as its percentage amount which is used to determine the molecular formula of the complex. The complexes of $\mathrm{Sn}$ (II) and $\mathrm{Pb}$ (II) were decomposed separately using concentrated of $\mathrm{HNO}_{3}$, to remove the organic component and the metal ions were tested as follows.

$\mathrm{Sn}$ (II) was tested with addition of $\mathrm{AgNO}_{3}$ solution and observed the characteristic color. A few drops of silver nitrate was added to a nitric acid solution of the $\mathrm{Pb}$ (II) ion solution and observed the characteristic color. 


\subsection{Magnetic Susceptibility Measurement}

The following calculations were made to arrive at the magnetic moments of the metal in the complex [36].

$$
\chi_{\mathrm{M}}=\chi_{\mathrm{g}} \mathrm{x} \text { M.wt. }
$$

where,

$\chi_{\mathrm{M}}$ - molar magnetic susceptibility $\left(\mathrm{cm}^{3} \mathrm{~mol}^{-1}\right)$,

$\chi_{\mathrm{M}^{-}}$-gram magnetic susceptibility $\left(\mathrm{cm}^{3} \mathrm{~g}^{-1}\right)$,

M.wt. $\left(\mathrm{g} \mathrm{mol}^{-1}\right)$.

The $\chi_{\mathrm{M}}$ is subjected to diamagnetic correction using Pascal constants to obtain corrected magnetic susceptibility $\left(\chi_{\mathrm{M}}{ }^{\text {corr }}\right)$, the magnetic moment is finally calculated as: $\mu_{\mathrm{eff}}=2.828\left(\chi_{\mathrm{M}}{ }^{\text {corr }} \text {. T }\right)^{1 / 2}$

where,

$\mu_{\text {eff }}$ - magnetic moment and $\mathrm{T}$ - temperature in $\mathrm{K}$

Then from the effective magnetic moment $\left(\mu_{\text {eff }}\right)$ obtained, the number of unpaired electrons can be calculated using the relation: $\quad \mu_{\mathrm{eff}}=[\mathrm{n}(\mathrm{n}+2)]^{1 / 2}$

where,

$\mathrm{n}$ - number of unpaired electrons.

\subsection{Chloride Estimation}

About $0.2 \mathrm{~g}$ of solid $\mathrm{AgNO}_{3}$ was dissolved in $250 \mathrm{~mL}$ conical flask with $20 \mathrm{~mL}$ of distilled water. The solution was stored in brown bottles for further uses, and $6 \mathrm{M}$ of $\mathrm{HNO}_{3}$ was used for washing the precipitate followed by $50 \mathrm{~mL}$ of distilled water and silver chloride was isolated. Approximately $0.2 \mathrm{mg}$ amount of each complex was decomposed in $6 \mathrm{M}$ concentrated $\mathrm{HNO}_{3}$ and heated on oil bath for one hour at $100^{\circ} \mathrm{C}$.

The samples were dissolved in $100 \mathrm{~mL}$ of deionized water containing $3 \mathrm{~mL}$ of $6 \mathrm{M} \mathrm{HNO}_{3}$ and stirred slowly with glass rod and digested the $1 \mathrm{ml}$ of $0.1 \mathrm{M} \mathrm{AgNO}_{3}$ solution. The contents were further digested for 10 minutes.The precipitation was checked for completeness in adding two more drops of $0.1 \mathrm{M}$ $\mathrm{AgNO}_{3}$ to the supernatant liquid. Then the resulting precipitate was filtered through a cleaned, dried and weighed crucible. After filtration, the resulting precipitate was placed in a large beaker covered with a watch glass and dried at $120^{\circ} \mathrm{C}$ for 2 hours in hot air oven. The amount of chloride was calculated according to the standard method [37].

Mass of chloride $=\mathrm{m}_{\mathrm{AgCl}} \times 0.24736$

Then, the amounts of chloride in the complexes have been calculated as follows:

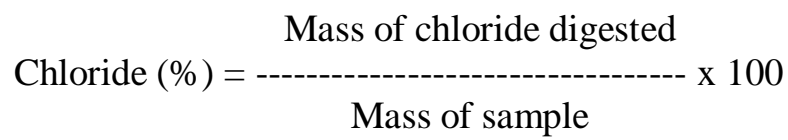

\section{Results and Discussion}

Usually Schiff bases and complexes of transition metal ion used for industrial, pharmaceutical and biological applications. But still there is need to explore the coordination ability of Schiff base ligand with metalloid elements such as tin and lead. This is because, both are non-transition elements and the survey of literatures show that there is shortage of information on tin (II) and lead (II) complexes. The studied Schiff base of benzylideneaniline was obtained in good percentage yield $(90.61 \%)$, with a sharp melting point of $62^{\circ} \mathrm{C}$. The percentage yields of tin (II) and lead (II) complexes were obtained as $71.1 \%$ and $67.8 \%$ respectively. The color of the tin (II) and lead (II) are found in green yellow and greenish white with melting points $58^{\circ} \mathrm{C}$ and $61^{\circ} \mathrm{C}$ respectively. This shows that the prepared complexes are consist of more off tin and lead are further confirmed with their respective boiling points.

\subsection{Fourier Transform Infrared Spectroscopy (FTIR) Study}

The FTIR spectroscopy is among one of the most powerful tools to characterize the functional groups, especially organic compounds and also for inorganic complexes at some extent. The FTIR spectrum of the ligand and both complexes were obtained in the range $4000-400 \mathrm{~cm}^{-1}$ using $\mathrm{KBr}$ pellet [38]. In order to determine the coordination sites of the ligand in the complexes, the IR spectrum of the ligand was compared with the IR spectrum of the two complexes. A broader stretching vibration was observed around $3434 \mathrm{~cm}^{-1}$, which possibly corresponds to $\mathrm{O}-\mathrm{H}$ stretching of water from any moisture available. The appearance of a new band at $3061 \mathrm{~cm}^{-1}$ attributed to C$\mathrm{H}$ stretch of $=\mathrm{C}-\mathrm{H}$, which indicates the involvement of medium aromatic and alkenes groups in the ligand. A new prominent band at $1658 \mathrm{~cm}^{-1}$ is shown due to azomethine $v(\mathrm{C}=\mathrm{N})$ linkage in the ligand (shown in Figure 1), which indicates that condensation between benzaldehyde and amino group of aniline has taken place resulting the formation of desired Benzylideneaniline ligand. The comparison of the IR spectra of the ligands with their Sn (II) and $\mathrm{Pb}$ (II) complexes showed a major shift from $1658 \mathrm{~cm}^{-1}$ to lower wave numbers $1626 \mathrm{~cm}^{-1}$ and $1628 \mathrm{~cm}^{-1}$. This is suggesting that the coordination of the azomethine nitrogen with the $\mathrm{Sn}$ (II) and $\mathrm{Pb}$ (II) ions. On both of the complexes the presence of $v(\mathrm{~Pb}-\mathrm{N})$ and $v(\mathrm{Sn}-\mathrm{N})$ vibration observed in the region $575-671 \mathrm{~cm}^{-1}$ [39]. In addition, there are bands corresponds to the peaks of $1019 \mathrm{~cm}^{-1}$ for $v(\mathrm{Sn}-\mathrm{Cl})$, and $767 \mathrm{~cm}^{-1}$ for $v(\mathrm{Sn}-\mathrm{Cl})$. Another important band is observed around at 1434 
$\mathrm{cm}^{-1}$ assigned for $v(\mathrm{~Pb}-\mathrm{N})$ and $921 \mathrm{~cm}^{-1}$ forv $(\mathrm{Pb}-\mathrm{Cl})$ (Figures $2 \& 3$ ).

Additional bands also appeared that corresponds to wave length $1936 \mathrm{~cm}^{-1}(\mathrm{C}-\mathrm{H}$; aldehydes stretching bands), $1194 \mathrm{~cm}^{-1}\left(\mathrm{C}-\mathrm{N}\right.$, stretching), $1172 \mathrm{~cm}^{-1}(\mathrm{C}=\mathrm{N}$; stretching of amine groups), $907 \mathrm{~cm}^{-1}(=\mathrm{C}-\mathrm{H}$; stretching of alkenes group) and $694 \mathrm{~cm}^{-1}(=\mathrm{C}-\mathrm{H}$; bending of alkenes groups), band at $1578 \mathrm{~cm}^{-1}$ corresponds to $\mathrm{C}=\mathrm{C}$ with aromatic functional group are shown strong bands for the ligand as shown in Figure 3.

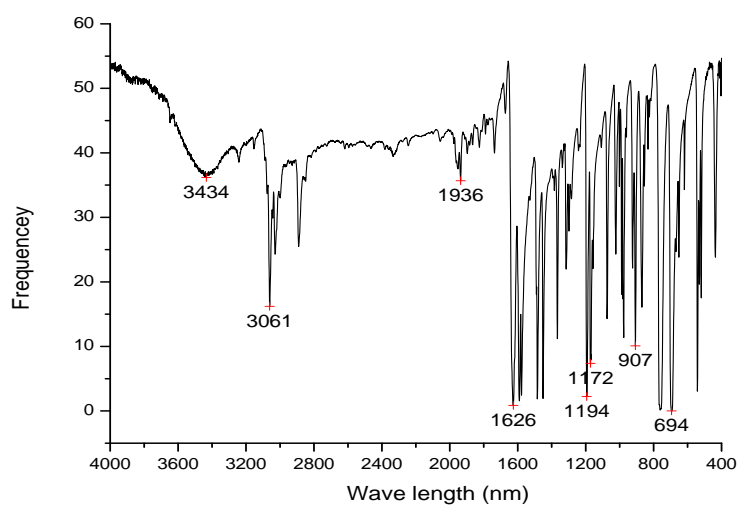

Figure.1 IR spectrum of benzylideneaniline ligand

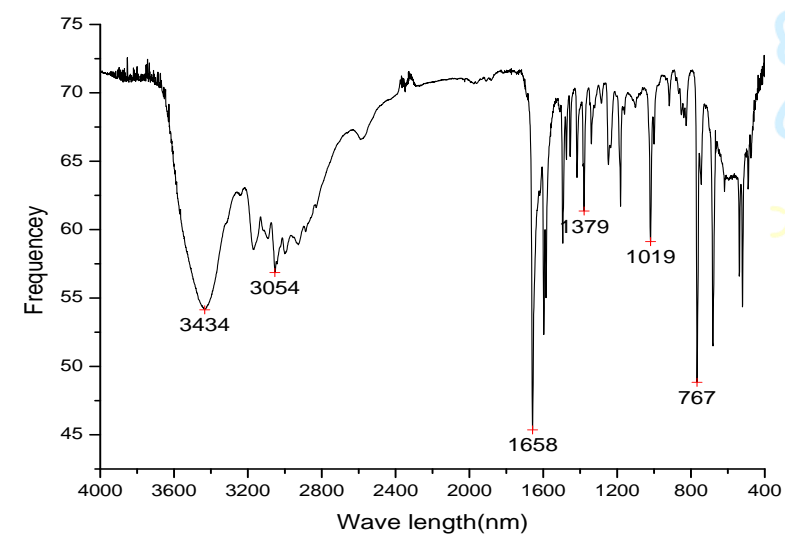

Figure 2. IR Spectra of Sn (II) benzylideneaniline complex

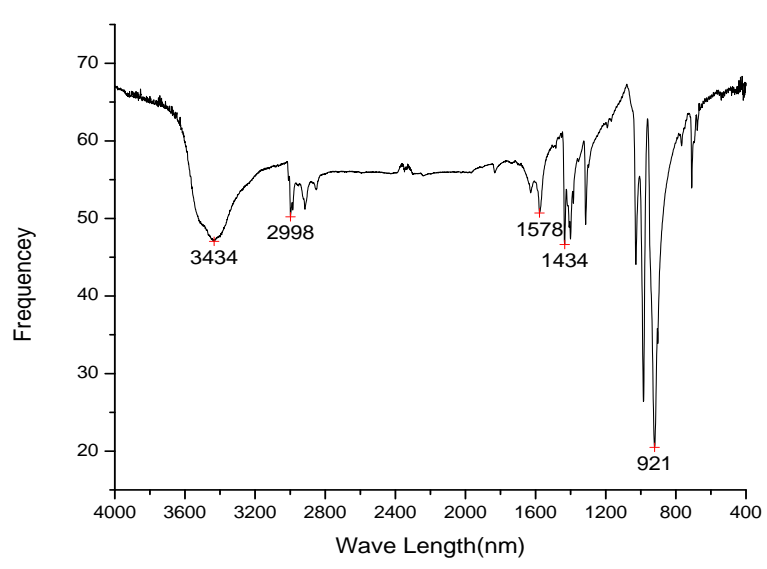

Figure 3. IR Spectra of $\mathrm{Pb}$ (II) Benzylideneaniline complex

\section{2 ${ }^{1} \mathrm{H}-\mathrm{NMR}$ Spectra of the Study}

The ${ }^{1} \mathrm{H}-\mathrm{NMR}\left(\mathrm{CDCl}_{3}, \delta \mathrm{ppm}, 400 \mathrm{MHz}\right): 1.00$ (stretch, $3 \mathrm{H}$ ), 2.07 (medium, 4H), $3.04(2 \mathrm{H}), 2.12$ (medium,4H, $2 \mathrm{H}), 8.004,8.017,8.52$ and 10.072 (stretch, $1 \mathrm{H}, \mathrm{NH}$ ), 7.6-7.99 (medium, 5H, aromatic) and 7.32-7.58 (medium, 6H, aromatic); ${ }^{13} \mathrm{C}-\mathrm{NMR}\left(\mathrm{CDCl}_{3}, \delta \mathrm{ppm}\right)$ : 192.49;160.52 $(\mathrm{C}=\mathrm{N}), 152.12(\mathrm{C}=\mathrm{O}), 136.56(\mathrm{C}=\mathrm{H})$, $136.46,136.28,135.99,134.56,131.81,131.52$, $131.26,130.11,129.84,129.58,129.30,129.10$, $128.96,128.90,128.64,128.57,128.42,126.10$, $125.78,121.03,120.73,115.42$ (aromatic carbons), 77.59, 77.27, $76.96(\mathrm{CH})$ (Figures 4 and 5).

All these information's were reveals that the formation of amide functional group from the aldehydes and amine group of aniline in the Benzylidene aniline ligand.
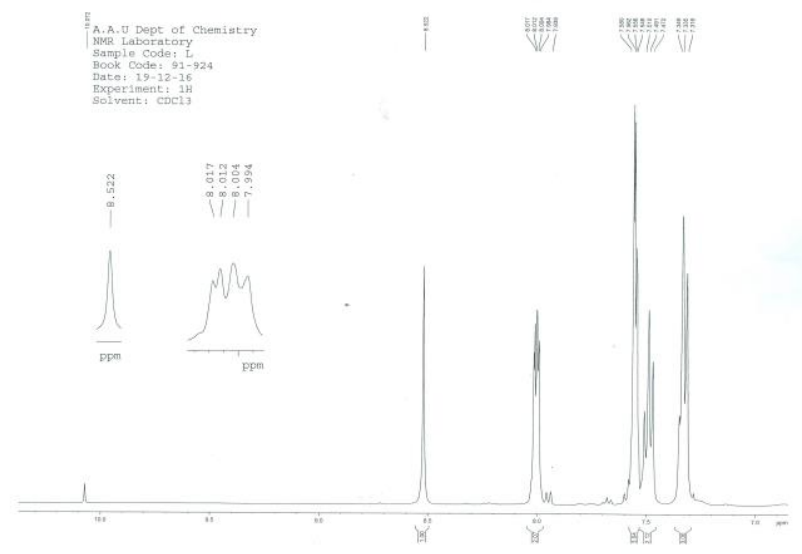

Figure 4. The ${ }^{1} \mathrm{H}-\mathrm{NMR}$ of benzylidene aniline ligand 

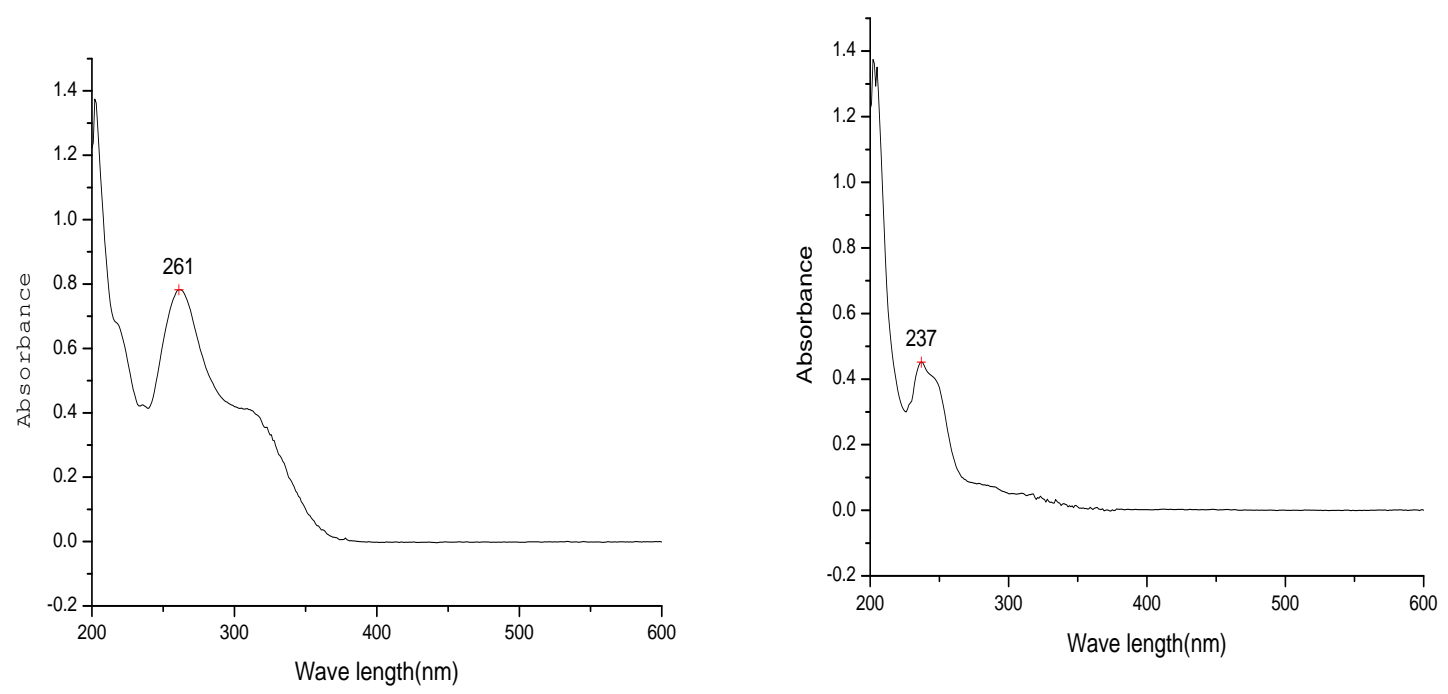

Figure 5. UV-Vis spectra of ligand

Figure 6.UV-Vis spectra of tin (II) complex

\subsection{UV-visible Spectrum of the Ligand, Tin (II)} and Lead (II) Complexes

It is helpful in determining the stereochemistry of the ligand and the complex based on the position and number of transitions peaks. In the electronic absorption spectrum of the ligand only one band was observed at $261 \mathrm{~nm}$ and this is attributed to $\pi \rightarrow \pi^{*}$ transition of the benzene ring of the ligands [40](see Figure.6). In both $\mathrm{Sn}$ (II) and $\mathrm{Pb}$ (II) complexes the bands are observed at $237 \mathrm{~nm}$ (Figures $7 \& 8$ ) is due to $\pi \rightarrow \pi^{*} \quad(\mathrm{C}=\mathrm{C}) \quad$ and $\quad \pi \rightarrow \pi^{*} \quad(\mathrm{C}=\mathrm{N})$ transitions respectively. This indicates a shift to shorter wave lengths due to complexation.

A band due to the $\mathrm{C}=\mathrm{N}$ chromophere in the spectrum of ligand at $261 \mathrm{~nm}\left(\pi-\pi^{*}\right.$ transition) shifted to a lower wave length in the spectra ofmetal complexes and appears at $237 \mathrm{nmin}$ the complexes. This clearly indicates the coordination of azomethine nitrogen to the metal atom. During the formation of the complexes these bands are shifted to lower wavelength suggesting that the nitrogen atom of the azomethine group is coordinated to the metal ion.

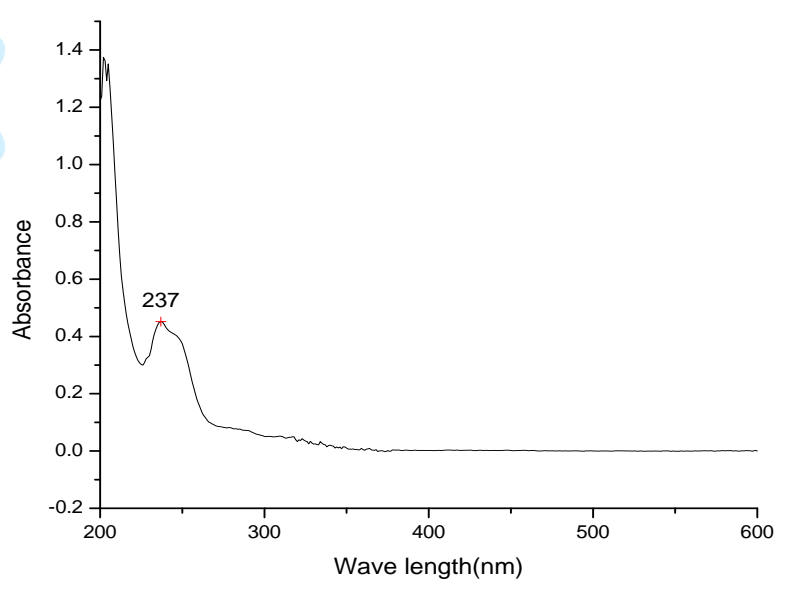

Figure 7. UV-Vis spectra of lead (II) complex

\subsection{Elemental Analysis of Ligand and both Complexes}

Elemental analysis results showed that there is a direct correlation between the calculated and the experimentally found values indicating the formation of the ligand with the formula $\mathrm{C}_{13} \mathrm{H}_{11} \mathrm{~N}$ and to both [Sn $\left.\left(\mathrm{C}_{13} \mathrm{H}_{11} \mathrm{~N}\right)_{2} \mathrm{Cl}_{2}\right]$ and $\left[\mathrm{Pb}\left(\mathrm{C}_{13} \mathrm{H}_{11} \mathrm{~N}\right)_{2} \mathrm{Cl}_{2}\right]$ complexes as shown in Table 1 . 
Table 1. Elemental analyses data of ligand and their complexes

\begin{tabular}{|c|c|c|c|c|}
\hline \multirow[t]{3}{*}{ Compounds } & \multirow{2}{*}{$\begin{array}{l}\text { Molecular } \\
\text { weight } \\
\text { (g/mol) }\end{array}$} & \multicolumn{3}{|c|}{ Elemental Analysis } \\
\hline & & $\mathrm{C}$ & $\mathrm{H}$ & $\mathrm{N}$ \\
\hline & $\begin{array}{c}\text { Calculated } \\
\text { (Found) }\end{array}$ & $\begin{array}{l}\text { Calculated } \\
\text { (Found) }\end{array}$ & $\begin{array}{l}\text { Calculated } \\
\text { (Found) }\end{array}$ & $\begin{array}{l}\text { Calculated } \\
\text { (Found) }\end{array}$ \\
\hline$\underline{\mathrm{C}_{13} \mathrm{H}_{11} \mathrm{~N}}$ & $181(180.7)$ & $86.18(86.2)$ & $6.08(6.1)$ & $7.73(7.7)$ \\
\hline$\underline{\mathrm{Sn}\left(\mathrm{C}_{13} \mathrm{H}_{11} \mathrm{~N}\right)_{2} \mathrm{Cl}_{2}}$ & $552(551)$ & $56.5(56.6)$ & $3.98(4.0)$ & $5.07(5.1)$ \\
\hline$\left[\mathrm{Pb}\left(\mathrm{C}_{13} \mathrm{H}_{11} \mathrm{~N}\right)_{2} \mathrm{Cl}_{2}\right]$ & $640(638.9)$ & $48.7(48.8)$ & $3.43(3.44)$ & $4.37(4.40)$ \\
\hline
\end{tabular}

From the above table, generalize the following information;

a. The elemental analysis (\%) calculated for the ligand, $\mathrm{C}_{6} \mathrm{H}_{5} \mathrm{CH}=\mathrm{NC}_{6} \mathrm{H}_{5}$ are: $\mathrm{C} \quad-86.18$; $\mathrm{H}-6.08 ; \mathrm{N}-7.73$ with molecular weight 181.00 $\mathrm{g} / \mathrm{mol}$ and the experimental values are found $\mathrm{C}$ 86.2; $\mathrm{H}-6.1$ and $\mathrm{N}-7.7$ with the molecular weight about $180.7 \mathrm{~g} / \mathrm{mol}$; whose analytical data are well consistent with molecular formula of the ligand.

b. The elemental analysis data are well consistent with molecular formula of Sn (II) complexes. Thus, the data calculated such as $\mathrm{C}-56.5 ; \mathrm{H}-3.98$ and $\mathrm{N}$ 5.07 with molecular weight $552.0 \mathrm{~g} / \mathrm{mol}$, while the elemental analysis of the present study was found in the tin complex are $\mathrm{C}-56.6 ; \mathrm{H}-4.00$ and $\mathrm{N}-5.1$ with the molecular weight $551 \mathrm{~g} / \mathrm{mol}$.

c. The calculated elemental analysis data of $\mathrm{Pb}$ (II) complex are stated $\mathrm{C}-48.7 ; \mathrm{H}-3.43$ and $\mathrm{N}-4.37$ with the molecular weight is $640.0 \mathrm{~g} / \mathrm{mol}$ and the elemental composition of $\mathrm{Pb}$ complex in this current study was found to be $\mathrm{C}-48.8 ; \mathrm{H}-3.44$ and $\mathrm{N}-4.4$ with the molecular weight $638.9 \mathrm{~g} / \mathrm{mol}$. Thus, the studied results were well agreed with theoretical (calculated) value, which confirmed that the studied ligand is well complexes with the $\mathrm{Sn}$ and $\mathrm{Pb}$ metal ions.

\subsection{Molar Conductance of Complexes}

The molar conductance of both Sn (II) and $\mathrm{Pb}$ (II) complexes were determined by taking $0.02 \mathrm{M}$ solution of each complex in methanol solution and the cell constant determination was made by using the standard calculations.

a. The Molar conductance of the Sn (II) complex resulted from the solution of methanol was found as $1.53 \times 10^{-3}(76.62) \Omega^{-1} \mathrm{~mol}^{-1} \mathrm{~cm}^{-1}$ (Table 2) and corresponds to the own ions.

b. The Molar conductance of the $\mathrm{Pb}$ (II) complex resulted from the solution of methanol was established as $1.82 \times 10^{-3}(91.21) \Omega^{-1} \mathrm{ohm}^{-1} \mathrm{~cm}^{-1}$ which is corresponds to their own ion.
These molar conductance values (see Table 2) showed that the non-electrolytic nature of both $\mathrm{Sn}$ (II) and $\mathrm{Pb}$ (II) complexes.

\subsection{Magnetic Susceptibility}

The magnetic moment values for both $\mathrm{Sn}$ (II) and $\mathrm{Pb}$ (II) complexes are zero (Table 2), which indicate that they are diamagnetic. The magnetic properties of the complexes have weak magnetic moment or slightly interacted with the magnetic fields. When, the electron configuration of both $\mathrm{Sn}$ (II) and $\mathrm{Pb}$ (II) complexes such as ${ }^{50} \mathrm{Sn}$ is $[\mathrm{Kr}] 4 \mathrm{~d}^{10} 5 \mathrm{~S}^{2} 5 \mathrm{P}^{0}$ and for ${ }^{82} \mathrm{~Pb}$ is [Xe] $5 \mathrm{~d}^{10} 6 \mathrm{~S}^{2} 6 \mathrm{P}^{0}$ whose all electrons are paired. Therefore, in both cases, there are no unpaired electrons and no permanent magnetic moment per atom that reported in literature [41]. According to electronic configuration of $\mathrm{Sn}(\mathrm{II})$ and $\mathrm{Pb}$ (II) complexes, four atomic orbital undergo hybridization resulting four $\mathrm{sp}^{3}$ hybrid orbital's. Such hybrid orbitals are commonly employed in complexes with square planar geometry around the central metal ion [41].

Table 2: Analytical Data of ligand and the two Synthesized Complexes

\begin{tabular}{lcccc}
\hline Complexes & $\begin{array}{c}\text { Melting } \\
\text { point } \\
\left({ }^{0} \mathrm{C}\right)\end{array}$ & $\begin{array}{c}\% \\
\text { yield }\end{array}$ & Conductivity & $\begin{array}{c}\text { Magnetic } \\
\text { moment }\end{array}$ \\
\hline $\mathrm{C}_{13} \mathrm{H}_{11} \mathrm{~N}$ & 62 & 90.6 & - & - \\
\hline & 58 & 71.1 & $1.53 \times 10^{-3}(76.62)$ & 0
\end{tabular}

$\operatorname{Sn}\left(\mathrm{C}_{13} \mathrm{H}_{11} \mathrm{~N}\right)_{2} \mathrm{Cl}_{2}$

$\begin{array}{llll}61 & 67.8 & 1.82 \times 10^{-3}(91.21) & 0\end{array}$

$\left[\mathrm{Pb}\left(\mathrm{C}_{13} \mathrm{H}_{11} \mathrm{~N}\right)_{2} \mathrm{Cl}_{2}\right]$

All the synthesized compounds were stable in air and has higher melting points of the ligand than that of their corresponding complexes (see Table 2), reveals that the ligands were much more stable than those complexes.

Mostly, the necessity of determining chloride ion estimation in the complex is to confirm whether the chloride ion is present in the complex or not. The amount of chloride is calculated from the amount of $\mathrm{AgCl}$ precipitated and compared with the theoretical results for the proposed formula of metal complexes, which in depicted in Table 3. Therefore, this analytical data is in supports of molar conductance measurements and there is no chloride ions were found outside of the coordination sphere. Therefore, the present study confirms that the chloride ions were present within the coordination sphere of both complexes of Sn (II) and $\mathrm{Pb}$ (II). 
Table 3.Results of chloride ion contents in complexes

\begin{tabular}{|c|c|c|c|c|c|c|c|}
\hline \multirow{2}{*}{ Compounds } & \multirow{2}{*}{ 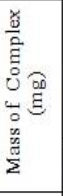 } & \multicolumn{2}{|c|}{ Mass of $\mathrm{AgCl}(\mathrm{mg})$} & \multicolumn{2}{|c|}{$\begin{array}{l}\text { Mass of Chloride } \\
\text { Obtained (mg) }\end{array}$} & \multicolumn{2}{|c|}{$\begin{array}{l}\% \text { of Chlorides in the } \\
\text { Complexes }\end{array}$} \\
\hline & & $\begin{array}{l}\text { Before } \\
\text { digested }\end{array}$ & $\begin{array}{c}\text { After } \\
\text { digested }\end{array}$ & $\begin{array}{l}\text { Before } \\
\text { digested }\end{array}$ & $\begin{array}{c}\text { After } \\
\text { digested }\end{array}$ & $\begin{array}{l}\text { Before } \\
\text { digested }\end{array}$ & $\begin{array}{c}\text { After } \\
\text { digested }\end{array}$ \\
\hline$\left[\mathrm{Sn}\left(\mathrm{C}_{13} \mathrm{H}_{11} \mathrm{~N}\right)_{2} \mathrm{Cl}_{2}\right]$ & 0.20 & 0 & 0.1487 & 0 & 0.0368 & 0 & 18.40 \\
\hline$\left[\mathrm{Pb}\left(\mathrm{C}_{13} \mathrm{H}_{11} \mathrm{~N}\right)_{2} \mathrm{Cl}_{2}\right]$ & 0.22 & 0 & 0.1330 & 0 & 0.0329 & 0 & 14.95 \\
\hline
\end{tabular}

\subsection{Proposed Structure of Ligand}

Thus, the studied results of elemental analysis, IR and NMR data the structural formula of Benzylidene aniline (Figure 9) is predicted, confirmed and agreed with existing as:

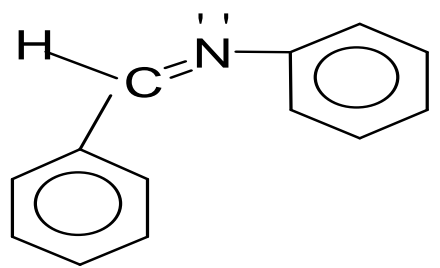

Figure 9.Proposed structure of synthesized Benzylideneaniline (planar $\mathrm{sp}^{2}$ hybrid orbital)

\subsection{Proposed Structure of Organo tin and Organo lead Complexes}

The chloride ion determinations showed that chloride ions are present in the two complexes. Then, the chloride ions are in the inner sphere. Therefore, the proposed structures of both metal complexes are clarified further from the results of UV-Visible, magnetic susceptibility, FT-IR spectral studies, elemental analysis, ${ }^{1} \mathrm{H}-\mathrm{NMR}$ and ${ }^{13} \mathrm{C}-\mathrm{NMR}$. Thus, the structures of both complexes are conformed and presented in figures 10 and 11 .

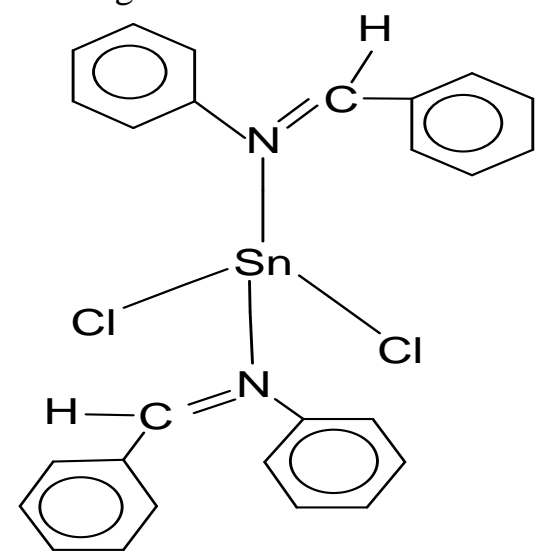

Figure 10. Proposed structure of $\left[\mathrm{Sn}\left(\mathrm{C}_{13} \mathrm{H}_{11} \mathrm{~N}\right)_{2} \mathrm{Cl}_{2}\right]$

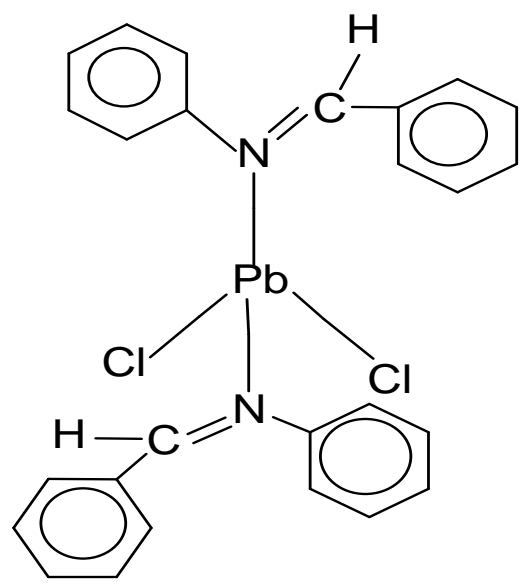

Figure 11. Proposed structure of $\left[\mathrm{Pb}\left(\mathrm{C}_{13} \mathrm{H}_{11} \mathrm{~N}\right)_{2} \mathrm{Cl}_{2}\right]$

Thus from all the studied data and spectral results are revealed consistent for the molecular formulae of the ligand and both complexes; the proposed geometry of both complexes are square planar and both have diamagnetic nature.

\section{Conclusions}

Benzylideneaniline Schiff base was successfully synthesized by condensation of benzaldehyde and aniline. The $\mathrm{Sn}$ (II) and $\mathrm{Pb}$ (II) complexes of the ligand were synthesized through a direct method. The ligand and the complexes were characterized using elemental analysis, molar conductivity, UV-Vis, FT-IR, NMR spectroscopy and chloride determination. The IR spectra are shows that the ligand is bonded to the metals through carbon-nitrogen atom lone pair. The conductivity measurement of the complexes confirmed that the complexes are non-electrolytes. Furthermore, chloride ion determination showed that chloride ions are present in the complexes. While the complexes are non-electrolyte but contain chloride ions. Then, the chloride ions are in inner sphere complex bonded to the central of $\mathrm{Sn}$ (II) and $\mathrm{Pb}$ (II). Based on the analytical data, the studied complexes have monodentatebenzylideneaniline ligand with the chloride ions in their inner coordination sphere and propose that the structures of the complexes are square planar.

\section{Recommendations}

In order to establish the proposed structure $\mathrm{x}$-ray crystal structure of the complexes should be obtained. The applications of the complexes can be studied in different fields such as antimicrobial, insecticidal, antiknocking agent in petrol, diesel and gasoline as an alternative for tetraethyl lead. 


\section{Acknowledgement}

I would like to thank Department of Chemistry,Arba Minch University for facilitated the laboratory for working.

\section{References}

[1]. Anand P., Patil M., Sharma K., Khosa L. and Masand N. (2012); "General reaction mechanism of Hugo Schiff bases"; J. Int. Drug Disco. 3; 851-866.

[2]. Yang Z. and Sun P. (2006); "Compare of three ways of synthesis of simple Schiff base"; J. Int. Mol. Sci. 6; 12-14.

[3]. Dobbs P., Rossiter S., Alan K., Taylor K., Eds and Elsevier, (2005); "Uses of Schiff bases for the synthesis of imines or as ligands "; J. Ind. Chem. 43; 419-450.

[4]. Westheimer F.H. and Taguchi K. (1971); "Reaction of Aldehydes and Ketones with Amine" J. Org. Chem. 36; 1570-1572.

[5]. Shiraishi Y., Ikeda M., Tsukamoto D., Tanaka S. and Hirai T. (2011); "Aerobic Oxidative Synthesis in the Preparation of Schiff's Bases"; J. Chem. Commun. 2011; 47-48.

[6]. Hoesch, K. and BerDtsch. (1917); "Reaction of Phenols and Phenol-Ethers with Nitriles"; J. Chem. Ges. 50; 462-468.

[7]. Houben, J. and Fischer W. (1929); "Reaction of Phenols and Phenol-Ethers with Nitriles"; J. Prakt. Chem., 123; 262-313.

[8]. Jayandran M. and Balasubramanian V. (2012) "The importance of schiff base complexes for bioinorganic chemistry"; J. Int. App. Chem. 4(1); $1-8$.

[9]. Muhammed H. and Jayandran M. (2014); "The Schiff base complexes have potentially biological interest being used as models of biological compounds"; J. Nat. Prod. Res. 4(3); 82-87.

[10]. Raman N., Joseph J. and Muthu K. (2008)"Antimicrobial Investigation of drug research and biocidal activities of Schiff bases"; J. Ind. Pharm. \&Biopest. 1; 206-207.

[11]. Bharti K., Nath G., Tilak R. and Singh S.( 2010);“Antibacterial activities of new Schiff base metal complexes synthesized from 2-hydroxy-1naphthaldehyde and 5-amino-1-naphthol", J. Euro. Med. Chem.45; 651-660.

[12]. Solak N., Rollas S. and Arkivo C. (2006); "Synthesis, spectroscopic, anti-tuberculosis and cytotoxic studies of biologically active new Schiff Bases", J. Iran. Chem. Soc.8; 173-7174.

[13]. Wadher S., Puranik M., Karande N. and Yeole P. (2009) "Antibacterial activities of new Schiff base and metal complexes synthesized from 2-hydroxy- 1-naphthaldehyde and 5- amino-1-naphthol," J. Int. Pharm. Tech. Res. 1; 22-24.

[14]. Verma M., Pandeya S., Singh, K. and Stables P.J. (2004); "Anticonvulsant activity of Schiff bases of isatins derivatives"; J. As. Acta Pharm. 54(1); 4956.

[15]. Wanda R., Violetta P. and Jerzy L. (2005); "The Commercial significant of organometallic compounds containing Lead and lead and Tin"; J. Coord. Chem.Rev.249; 2156- 2175.

[16]. Ahamadi S., Ali. S., Shahzadi S. and Ahmed F. (2005); "Production of organotin compounds with novel Schiff base ligand"; J. Turk. Chem. 29; 299308.

[17]. Beltran H. I., Rivera L. S. Z., Mancilla T., Santillan R. andFarfan N. (2003); "Spectra of Sn(II) ions, $\mathrm{Pb}$ (II) ions and ligandsChemistry"; J. Am. Chem.9(10); 2291-2306.

[18]. Yin H. D., Hong M., Wang Q. B., Xue S. C. and Wang D. Q.(2005); "The Condensation reaction between aldehyde/ketone and amino acid resulting the desired ligands"; J. Organomet. Chem.690 (6); 1669-1676.

[19]. Ali S.A, Soliman A.A., Aboaly M.M. and Ramadan R.M. (2002); "Coordination of Schiff bases to metal complexes through the nitrogen atom"; J. Coord. Chem.55; 1161-1162.

[20]. H. L. Singh and A. K. Varshney A.K.(1999); “ The comparison of the IR spectra of the ligands with their $\mathrm{Sn}$ (II) and $\mathrm{Pb}$ (II) complexes of azomethine nitrogen", J. Main Group Metal Chem.22(9);529 532.

[21]. Gupta N. S., Mohan M., Jha N. K. and W. E. (1991); "The comparison of the IR spectra of the ligands with their $\mathrm{Sn}(\mathrm{II})$ and $\mathrm{Pb}(\mathrm{II})$ complexes showed a major shift to lower wave numbers in azomethine.

[22]. Singh H.L. Sharma M. and Varshney A.K. (2000);"Synthesis and Reactivity in Inorganic and Metal OrganicChemistry"; J. Ind. Chem. Soc.30; 445-456.

[23]. Choudhary M. A., Mazhar M., Ali S., Salma U., Ashraf S. and Malik A. (2002); "The appearance of new bands in the metal complexes"; J.Turkish.Chem.26(1); 125-131.

[24]. Nath M., Singh H., Eng G., Song X. and Kumar A. (2009); "InorganicChemistry Communications"; J. Iran. Chem. Soc. 12(10); 1049-1052.

[25]. Saraswat B. S., Srivastava G. and Mehrotra R.C. (1979; "Organotin compounds as transesterification catalysts"; J. Organo Metallic Chem.164(2); 153158.

[26]. Singh H. L. (2011); "Syntheses and luminescence behavior of terephthalate bridged lead (II) 
complexes with tetradentate N-donor Schiff bases"'; J. Adv. Phys.Chem. 37(8); 1087-1101.

[27]. Osowle A. A. (2008); "Syntheses and Characterization of Some Tetradentate Schiff-Base Complexes and their Heteroleptic Analogues"; J. Eur. Chem.5; 130-131.

[28]. Garg A. Tondon J.P. (1987); "Electronic spectra of inter-ligand and charge transfer of $n-\pi *$ transitions"; J. Trans. Met. Chem. 12; 212-214.

[29]. Abdlseed F. A. and El-ajaily M. M. (2009); "The study of P(II) complexes of the hybridization and Intra- ligand charge transfer"; J. Inter. Pharm. Res. 1(4);1097-1103.

[30]. Arounaguiria S., Easwaramoorthya D, Ashokkumara A. and Maiyaa B.G. (2000); "Cobalt(III), nickel(II) and ruthenium(II) complexes of 1,10-phenanthroline family of ligands: DNA binding and photo cleavage Studies"; J. Ind. Acad. Sci. 112;1-2.

[31]. Sheida E., Khadijeh S., Ghazal M., Mohammad S. and Khosro M. ( 2015); "Coordination sphere and physico-chemical techniques of synthesized and characterization of Ligands and tin(IV) complexes by ${ }^{1} \mathrm{H}-\mathrm{NMR}, \quad{ }^{119} \mathrm{Sn}$ NMR, IR and mass spectroscopy analysis"; J. Act. Chim.Slov.62; 805817.

[32]. AnjaniSolankee and Indrajit Th. (2006); "Synthesis and spectral study of Schiff base ligands"; J. Ind. Chem. 45(2); 517-522.

[33]. Svehla G. V.(1996); “ Qualitative Inorganic Analysis chloride test"; J. Eur. Chem. Soc. 0;143151.

[34]. Faten Z., Atef A., Ramadan T., Mohamed M. and Fouz M. (2015); "Synthesis and Characterization of Metal Complexes of Schiff's Base Ligands Derived from 4-CarboxyHydrazide-5, 6-Diphenyl-3[2-H] Pyridazone' '; J. Modern Chem.3(1); 15-26.

[35]. Kumar S., Kishore D. and Mehta R.K. (2000); "Direct Electrochemical Synthesis of Organotin and Organolead Compounds with pyridine-2 thione Ligands', J. Ind. Chem. Soci. 77; 254-256.

[36]. Tanna M., Gomes C. and Heloisa B. (1999); "Nickel(II) and Copper(II) complexes of bidentate Heterocyclic Thiosemicarbazone"; .J. Braz. Chem. Soc. 10;184-185.

[37]. Siddappa K., Reddy T. and Reddy C.V. (2008); "Synthesis, Characterization and Antimicrobial Studies of 3-[(2-Hydroxy-quinolin-3-ylmethylene)amino]-2-phenyl-3H-quinazolin-4-one and its Metal Complexes"; J. Eur. Chem.5; 155-156.

[38]. Catherine E. House Craft and Alan G. Sharpe, (2005); "Properties and Magnetic susceptibility of metal complexes"; J. Inorg. chem. 2nd ed. 2; 581585.
[39]. Wajid R., Musa K.B., Amin B. and Saqib A. (2005); "Synthesis and Characterization of Biologically Potent Di-organotin (IV) complexes of Mono-Methyl Glutarate'; J. Chin. Chem. Soc. 52(2); 231-236.

[40]. Senthilkannan K. and Gunasekaran S. (2013); "Spectroscopic Studies, chloride estimation by gravimetric method and other Novel Studies of 4Bromo 4-Chloro Benzylidene Aniline (BCBA) Crystal and Non Linear Optical Material', J. Inter. Chem. Tech. Res. 5(6); 3051-3058.

[41]. Ahamad T, Nishat N. and Parveen S. (2008); "Coordination of the azomethine nitrogen with the $\mathrm{Sn}(\mathrm{II})$ and $\mathrm{Pb}(\mathrm{II})$ ions ',J. Coord. Chem., 61; 19631964. 